\title{
CONCEITO-AÇÃO DA DANÇA CONTEMPORÂNEA
}

Fanny Cacilie Gauna de Siqueira

Universidade Federal de Mato Grosso do Sul, Campo Grande, Mato Grosso do Sul, Brasil

Miraíra Noal Manfroi

Universidade Federal de Santa Catarina, Florianópolis, Santa Catarina, Brasil

Marcelo Victor da Rosa

Universidade Federal de Mato Grosso do Sul, Campo Grande, Mato Grosso do Sul, Brasil

Alcyane Marinho

Universidade Estadual de Santa Catarina, Florianópolis, Santa Catarina, Brasil

\begin{abstract}
Resumo
Os trabalhos coreográficos tidos como dança contemporânea abrangem diversas possibilidades, geram dúvidas, discussões e contradições. Nessa perspectiva, verificou-se o conceito de dança contemporânea a partir dos trabalhos apresentados por grupos de dança nos eventos na cidade de Campo Grande (MS). Trata-se de uma pesquisa descritiva, com abordagem qualitativa. Os resultados apontam que o conceito de dança contemporânea que os participantes possuem gira em torno das palavras-chave: biológico, estudo, expressividade, pluralidade, técnica e transformação. Ratificando que a dança contemporânea é uma linguagem que possibilita diversos outros estudos e interdisciplinaridade, restando aos envolvidos o interesse em desdobrá-la.
\end{abstract}

Palavras-chave: Dança; Conceito; Formação de conceito.

\section{Abrindo as cortinas}

Devido à propagação da dança contemporânea no universo das artes e do exercício físico, hodiernamente se tornou comum a apresentação de trabalhos coreográficos definidos como pertencendo a essa linguagem. Tais apresentações ocorrem em eventos em que academias especializadas em dança e escolas do ensino regular - que lecionam dança no contraturno - participam.

Nos eventos relacionados à dança, é comum os espectadores realizarem uma análise particular ou partilhada dos trabalhos que são apresentados ao público. A partir disso, acabam existindo julgamentos e preconceitos a respeito dos trabalhos alheios. Isso acontece em razão da dificuldade de conceituar ou definir uma vertente para cada coreografia, afinal esta é, na maioria das vezes, concebida entre quatro paredes.

Siqueira (2003) investiga a dança como arte e um interessante objeto de estudo da comunicação, podendo ser analisada dos pontos de vista técnico e estético. A autora parte da premissa que compreender uma dança implica em dominar o código cultural no qual ela se insere, contexto que se refere, tempo que foi criada e outros aspectos. $\mathrm{O}$ artista que expõe uma obra deixa de ser seu dono exclusivo para permitir que o público realize diversas interpretações. Dessa forma, a formação de plateias é um exercício contínuo, essencial para a comunicação entre o público e os artistas. 
Sendo, assim, acentuada por Siqueira (2003), a importância do artista-formador e do público receptivo para a construção e permeio da dança contemporânea. Por isso, se faz necessário o estudo prévio dos critérios utilizados para a conceituação de uma linguagem de dança, entender seu presente, investigar sua história e trajetória ao longo do tempo. Apesar da necessidade de conhecimento dos critérios de conceituação e de desdobramento teórico para o estudo geral da dança, existem poucos trabalhos publicados em relação à dança contemporânea, principalmente se tratando do estudo de sua conceituação.

O trabalho de Souza (2013) é o que mais se aproxima do estudo ora relatado, pois tem o objetivo de evidenciar qual a compreensão acerca da dança contemporânea que pessoas envolvidas em processo de formação na área das Artes possuem, enquanto o nosso trabalho não faz distinção de área de formação. Entretanto, assim como o nosso estudo, Souza (2013) não pretende criar um conceito em relação à dança contemporânea e, sim, evidenciar características e aspectos percebidos pelos indivíduos diretamente ligados à produção de obras artísticas pertencentes a essa linguagem.

Partindo dessas considerações, este trabalho tem como principal objetivo verificar o conceito de dança contemporânea a partir dos trabalhos apresentados coreograficamente em Campo Grande/MS, no período de maio a setembro de 2012. Especificamente, pretende analisar os critérios utilizados para a definição do conceito de dança contemporânea; identificar as referências práticas e teóricas que os grupos possuem para a construção de trabalhos contemporâneos e constatar como se dá o processo de montagem coreográfica dos mesmos.

\section{Primeiros passos}

De acordo com Duarte $(2008)^{1}$, a dança contemporânea surgiu nos anos 1960 com a pretensão de investigar novas possibilidades para o corpo na dança. Partindo do suposto histórico, o trabalho de Gil (2004) faz um ordenamento por meio dos precursores dessa linguagem artística. A obra trata de Merce Cunningham, que realizou uma revolução nos anos 1960. Esse artista provia-se de ideias em torno de noções do movimento abstrato; descentralização do espaço cênico; independência da música e dos movimentos; movimentação natural, orgânica, pura; o movimento que se expressa por si só.

Gil (2004) traz a renomada Pina Bausch, conhecida pelo uso de paradoxos como meio de criação de movimentos, criação de diferentes interpretações de elenco e do público, multiplicação dos pontos de vista induzindo à divergência, independente dos gostos subjetivos do espectador. Além desses artistas, Gil (2004) também trata de outros percursores da dança contemporânea na época: Steve Paxton, Valéry Matisse, Vaslav Nijinsky e Yvonne Rainer.

Em relação aos pioneiros brasileiros na dança contemporânea, um nome renomado é Angel Vianna, estudada por Freire (2004). Vianna aponta que desde que a dança foi codificada na corte do rei Luiz XIV, na França, a evolução da mesma foi passada oralmente entre as gerações. Dessa forma, o público experimenta e apenas tem ciência do produto estético apresentado no espetáculo, portanto desconhece o ponto de partida, os caminhos que os artistas percorrem em seu processo de criação, as experiências, parcerias, formação e construção de sua estética, logo, a projeção e disseminação das suas ideias que podem interferir na tradição da dança (FREIRE, 2004). Considerações que contribuem para justificar a realização deste trabalho, pois para conceituar uma obra artística, é necessário o conhecimento de sua concepção e desenrolar de sua trajetória.

\footnotetext{
${ }^{1}$ DUARTE, M. O que é a dança contemporânea? Jornalismo Porto Net. Porto, 2008. Disponível em: <http://jpn.c2com.up.pt/2008/12/22/o_que_e_a_danca_contemporanea.html>. Acesso em: 2 set. 2011.
} 
Snizek (2004) também aborda a dança contemporânea do Brasil, priorizando a carioca. Sendo que esta tem significativa referência e/ou origem na Europa, Estados Unidos e Ásia. O movimento pós-moderno americano, a dança expressionista alemã e a nova dança francesa influenciaram na composição do quadro da dança contemporânea brasileira atual.

Apesar de seu ecletismo, a dança contemporânea apresenta características estruturais ou até mesmo abstratas que se encontram presentes em grande parte dos trabalhos. Algumas dessas são citadas por Benvegnu $(2004)^{2}$, como: estrutura não linear, multiplicidade de significados, mudanças na configuração do tempo e do espaço, uso da tecnologia, liberdade de criação, entre outros. Dantas (2005) afirma que o termo dança contemporânea reveste inúmeras formas de dança e, em geral, é utilizado para abarcar diferentes poéticas atuais da dança, as quais não se enquadram nas classificações tradicionais, como balé e dança moderna.

A dança contemporânea é metafórica, isola os elementos do gesto e do corpo em unidades menores de percepção. Portanto, o dançarino torna-se um pesquisador do seu próprio corpo e do corpo alheio (SNIZEK, 2004). Logo, existe uma modificação no papel do dançarino, pois os coreógrafos tendem a solicitar que seus intérpretes participem dos processos de criação, que realizem atuações atléticas repletas de virtuosidade e nuances interpretativas, exercendo, então, um papel como cocriadores.

\section{O enredo}

Esta pesquisa é de caráter descritivo, pois, conforme Martins (2002, p. 36), “[...] tem como objetivo a descrição das características de determinada população ou fenômeno, bem como o estabelecimento de relação entre variáveis e fatos". Neste tipo de pesquisa, "[...] os fatos são observados, registrados, analisados, classificados e interpretados, sem que o pesquisador interfira neles" (ANDRADE, 2005, p. 98).

Os participantes do estudo, os quais são identificados por meio de nomes fictícios, foram seis diretores/coreógrafos de grupos de dança locais e de outros Estados - sendo estes escolares, não escolares, profissionais, amadores, independentes e/ou grupos de vínculo religioso - que apresentaram algum trabalho coreográfico conceituado como dança contemporânea entre os meses de maio e setembro de 2012, na cidade de Campo Grande, Mato Grosso do Sul.

Por meio do auxílio da Fundação Municipal de Cultura (FUNDAC), foi realizado um levantamento de todos os grupos que participaram ou realizaram eventos culturais e que contassem com a exposição de trabalhos nesta linguagem. Tais grupos foram contatados com o intuito de verificar se os mesmos iriam apresentar algum trabalho de dança contemporânea no período de análise estipulado.

Além disso, também foi contatada a FUNDAC para o fornecimento do calendário de eventos para que fossem levantados os eventos deste cunho artístico durante o determinado período de levantamento de dados, com vistas a atingir demais grupos, inclusive de outros Estados. Após a aproximação com todos os grupos de dança e saber a opinião dos mesmos em relação ao aceite de participação, foi estimado um calendário com todos os eventos a serem presenciados.

As apresentações coreográficas de dança contemporânea de cada evento passaram por observações sistemáticas e, ao término dessas, foram realizadas entrevistas, por meio de gravador, com os diretores/coreógrafos dos grupos. Depois do registro, transcrição da

\footnotetext{
${ }^{2}$ BENVEGNU, M. Por que é tão difícil pensar a dança contemporânea. Conexão Dança. Londrina, 2004. Disponível em: <http://www.conexaodanca.art.br/imagens/textos/artigos/Por\%20que\%20\%E9\%20t\%E3o\%20dif\%EDcil\%20pe nsar\%20a\%20dan\%E7a\%20contempor\%E2nea.htm\#>. Acesso em: 7 set. 2014.
} 
entrevista, análise e interpretação dos dados, os mesmos foram dialogados com o referencial teórico utilizado neste trabalho.

A análise dos dados foi feita por meio do método de categorização que realiza a análise de conteúdo, na qual as informações coletadas são organizadas em categorias. Para tanto, foi feita a organização e leitura do material, categorização, exploração do material, tratamentos dos resultados e a interpretação. Segundo Minayo (2007), para que haja uma categorização e amplitude na descrição, explicação e compreensão do foco em estudo, é importante garantir que as categorias sejam obtidas de maneira homogênea. Acredita-se que por meio desses dois métodos - apreciação visual da apresentação de cada trabalho e execução da entrevista ao final da mesma - a análise foi realizada de modo a gerar resultados significantes.

Para perguntas que constavam dados quantitativos foram feitas as médias numéricas para obtenção dos resultados. Para perguntas em que constavam dados qualitativos foi feito o levantamento de palavras-chave que apareceram com maior frequência diretamente das respostas dissertativas para o processo de análise.

Alguns dados entre as perguntas puderam ser agrupados por se tratarem de temas similares e que puderam ser relacionados com referências em comum, mas em sua maioria, as perguntas são apresentadas na análise de dados na mesma ordem em que o roteiro de entrevistas. Cada dado obtido pelas respostas é exposto seguido de explanação por meio de referência bibliográfica e análise dos autores.

\section{O espetáculo}

Houve 13 apresentações pertencentes à linguagem dança contemporânea durante o período de coleta de dados, porém as mesmas foram realizadas por sete grupos - sendo que alguns grupos se apresentaram mais de uma vez - e dois destes possuem o mesmo diretor e coreógrafo. Por isso, a coleta de dados se resumiu a seis diretores e/ou coreógrafos. Os trabalhos foram denominados como 'dança contemporânea' pelos próprios coreógrafos e diretores dos grupos e companhias, por isto o processo de coleta de dados se deu para/com eles. Outro aspecto a ser levado em consideração é que duas companhias que se apresentaram na cidade de Campo Grande (MS) neste período não são companhias locais, sendo uma de Florianópolis (SC) e a outra de São Paulo (SP).

A média de idade biológica dos entrevistados foi de 44,3 anos, sendo a menor idade 23 anos e a maior idade 60 anos. Em relação a esse fato, tem-se o tempo de atuação na área da dança com média de 26 anos, sendo que o menor tempo é de 14 anos e o maior tempo 34 anos. Vale ressaltar que essa atuação inclui a participação dos indivíduos como bailarinos (as), professores (as), produtores (as), coreógrafos (as), diretores (as), entre outros, em diversas linguagens da dança.

A média de idade representa uma idade adulta avançada, que em relação com o tempo de atuação na dança representa uma vasta experiência na área, inserida nos trabalhos desenvolvidos. A dança contemporânea exige do profissional de dança um maior senso crítico, sendo que este se desenvolve com maior experiência e idade. Ainda é possível analisar o tempo de atuação na área de dança contemporânea que os coreógrafos e diretores possuem, sendo a média de tempo 9,3 anos, com o menor tempo de dois anos e o maior tempo de 20 anos.

Ao questionar a data de início e a quantidade de trabalhos de dança contemporânea o grupo/companhia realizou, as respostas foram as seguintes: 


\begin{tabular}{ccc}
\hline Participante & $\begin{array}{c}\text { Quantidade de } \\
\text { Trabalhos Produzidos }\end{array}$ & Ano Inicial \\
\hline Douglas & 30 & 2003 \\
\hline Gabriela & 15 & 1998 \\
\hline Luan & 10 & 2007 \\
\hline Rafaela & 5 & 2009 \\
\hline Paulo & 5 & 2011 \\
\hline Talita & 4 & 2011 \\
\hline
\end{tabular}

É notória a diferença entre a média de tempo em que os coreógrafos e diretores atuam na área da dança em geral e a média de tempo de atuação na dança contemporânea, assim como é recente - em sua grande maioria - a produção de trabalhos na linguagem dança contemporânea. Conforme o Grupo de Pesquisas em Educação Física Escolar da Universidade de São Paulo (2011) ${ }^{3}$, a maioria das principais companhias de dança brasileiras que desenvolvem trabalhos com a linguagem da dança contemporânea, surgiu na década de 1990 e nos anos 2000, justificando então a atuação em média de 9,3 anos encontrada nas entrevistas.

Com relação à formação acadêmica e profissional dos entrevistados, Luan possui Doutorado em Educação, Gabriela possui formação acadêmica em Educação Física, Talita possui formação acadêmica em arquitetura e formação profissional em balé clássico, Douglas e Rafaela não possuem formação profissional e Paulo possui apenas formação profissional em balé clássico. Portanto, três pessoas que possuem formação formal e três pessoas que possuem formação informal, adquirida por experiência.

Ao analisar as profissões exercidas pelos entrevistados atualmente, todos afirmaram exercer mais de uma profissão, cinco são coreógrafos (Douglas, Gabriela, Luan, Rafaela e Paulo); quatro são professores de dança (Douglas, Gabriela, Luan e Paulo); três são diretores de companhia de dança (Gabriela, Luan e Paulo); um é professor do ensino formal (Luan) e uma é estudante (Talita).

Os bailarinos, dançarinos, coreógrafos e professores, integram a categoria dos ARTISTAS, profissão regulamentada pela Lei 6533/78. Com o novo CÓDIGO BRASILEIRO DE OCUPAÇÕES - CBO, os profissionais da dança passaram a ser denominados ARTISTAS DA DANÇA [...]. O artista da dança pode estudar e se tornar um profissional através de cursos livres nos estúdios, academias ou escolas, o que é considerado ensino informal. (CAMARGO, 2008, p. 19-20).

Pelos motivos descritos por Camargo (2008), foram encontrados nesta pesquisa, profissionais que não possuem formação formal para atuar como profissionais da dança. $\mathrm{Na}$ formação inicial em Dança e Artes Cênicas - não é o caso de nenhum dos entrevistados existe a graduação em licenciatura e bacharelado, assim como na formação em Educação Física - caso de um dos entrevistados.

De acordo com Ferraz (2000), existe uma tensão inegável entre os profissionais destas áreas, que se desenvolve a partir de alguns intelectuais e professores de dança que consideram os profissionais da Educação Física, de certa forma, incapacitados para trabalhar este conteúdo por considerar que estes, geralmente, trabalham a dança de maneira acrítica e superficial, enfatizando a abordagem tradicional. Por outro lado, Ferraz também argumenta que alguns profissionais da Educação Física se consideram no direito em desenvolver este

3 GRUPO DE PESQUISAS EM EDUCAÇÃO FÍSICA ESCOLAR - USP. A Dança Contemporânea no Tempo. São Paulo, 2011. Disponível em: <www.gpef.fe.usp.br/teses/agenda_2011_01.pdf> Acesso em: 30 jul. 2013. 
conteúdo devido a sua formação acadêmica e o estudo de conteúdos como anatomia, cinesiologia, atividades expressivas.

O Conselho Federal de Educação Física na Resolução 046/2002, dispõe sobre a Intervenção do Profissional de Educação Física e respectivas competências, definindo os campos de atuação. Sendo o profissional de Educação Física especialista em atividades físicas nas suas diversas manifestações, entre elas, ginásticas, exercícios físicos, desportos, jogos, lutas, danças, atividades rítmicas, expressivas e acrobáticas, musculação, lazer, recreação, reabilitação e demais. Assim como em outras áreas encontradas na pesquisa, a formação em Educação Física não deve ser encarada como um fator restringente para a atuação do profissional na dança, e sim como um fator positivo a acrescentar no desenvolvimento de trabalhos artísticos (CONSELHO FEDERAL DE EDUCAÇÃO FÍSICA, 2002).

Conforme Gariba e Franzoni (2007), muitas regiões brasileiras ainda não oferecem graduação em Dança e Artes Cênicas, portanto uma possibilidade é buscar no campo da Educação Física a inserção da dança em diversos ambientes, primordialmente, o universo escolar. Na graduação em Educação Física, é necessário o oferecimento de condições, que incluam em suas atribuições docentes a prática da dança na Educação Física, para que o aluno vivencie esta linguagem artística, e possa desenvolver uma atuação profissional na área que contribua para o desenvolvimento da capacidade criativa, descoberta de habilidades, formação de cidadão críticos, autônomos e conscientes.

Contudo, os cursos de graduação em Educação Física, durante a formação de futuros profissionais, exploram em demasia os conteúdos esportivos, sem aprofundar em conteúdos artísticos (SBORQUIA; GALLARDO, 2006). Segundo Rangel (2002), a maneira como é dado o enfoque para a dança durante a formação inicial em Educação Física pode explicar a pouca utilização da mesma em propostas no âmbito escolar e não escolar.

Em relação às diversas linguagens artísticas que o grupo/companhia realizou durante sua trajetória, todos afirmaram que realizaram trabalhos de dança contemporânea; cinco afirmaram que também realizaram trabalhos de jazz; dois de balé clássico; dois de balé moderno e um de dança folclórica. Quando questionados quais as linguagens de dança que o grupo/companhia estuda, participa de aulas e realiza pesquisas teórico-práticas atualmente, todos os entrevistados afirmaram que desenvolvem atividades relacionadas à dança contemporânea; três com o jazz; um com balé moderno e um com teatro. Nota-se uma forte presença do jazz nos trabalhos realizados, nas aulas e processos de montagem coreográfica.

Mundim (2005) ressalta que o jazz brasileiro dos anos 1990 e 2000 sofre forte influência dos procedimentos técnicos e coreográficos das danças moderna e contemporânea nas aulas e coreografias, por se tratar de um período em que essas danças vêm crescendo no país. Desde que não venha eliminar a história de outras linguagens artísticas, a comunicação entre elas pode ser proveitosa e servir de suporte e princípio para as novas tendências.

Ao questionar como os coreógrafos e diretores definem a dança contemporânea, foram encontradas e categorizadas palavras-chave devido ao índice de ocorrência nas respostas dos entrevistados, sendo elas: biológico; estudo; expressividade; pluralidade; técnica e transformação. Todas estas definições emitidas pelos entrevistados correspondem às referências utilizadas para a realização deste trabalho (BENVEGNU, 2004; DUARTE; VASCONCELOS; NASCIMENTO, 2006; DUARTE, 2008; FREIRE, 2004; GIL, 2004; SIQUEIRA, 2003; SNIZEK, 2004).

As respostas dos participantes abrangeram diversos aspectos da dança. Por exemplo, Douglas afirma que dança contemporânea "é uma forma de estudo e de trazer a dança para si, de forma mais consciente por meio de estudos teóricos ligados à anatomia, fisiologia e cinesiologia corporal"; Talita exprime ser "uma possibilidade de comunicação onde se é permitida fusões que estão em constante transformação", enquanto Luan trata dança 
contemporânea como "um estilo de dança que preza por uma expressão mais flexível; e que prioriza mais a transmissão de uma sensação do que uma maestria técnica".

$\mathrm{O}$ conceito com maior reincidência entre os referenciais teóricos utilizados neste estudo e de maior destaque entre as respostas dos coreógrafos/diretores é a pluralidade. Benvegnu (2004) trata do conceito de dança contemporânea relacionado com a multiplicidade de significados, discursos, temáticas, processos e produtos; Duarte (2008) argumenta que esta linguagem artística é aquela que permite novas possibilidades de movimentações corporais e de pensar a dança; Snizek (2004) ao comparar a dança contemporânea com outras linguagens afirma que ela é mais metafórica, pois isola os elementos do gesto e do corpo em unidades menores de percepção que são emolduradas como o objeto central de interesse e abstração através do tempo e da permissão para a multiplicidade. Dantas (2005) discute que a linguagem é utilizada para abarcar diferentes poéticas da dança nos dias de hoje as quais não se enquadram nas classificações tradicionais.

Ao tratar da dança contemporânea como um tipo de estudo, Freire (2004) traz Angel Vianna defendendo que os espectadores devem conhecer os caminhos que os artistas percorrem, em seu processo de criação; a projeção e disseminação das suas ideias que podem ou não interferir na tradição da dança. Para que isso ocorra, a montagem do trabalho deve ser recheada de estudos e referências. Snizek (2004) afirma que na dança contemporânea o dançarino torna-se um pesquisador do seu próprio corpo e do alheio. Observação, inquirição, experimentação, reflexão e expressão tornam-se objetivos da dança. Fazer, sentir e refletir tornou-se indissociáveis. A linguagem corporal é o objeto de estudo e de expressão privilegiado.

Ao se tratar de transformação, Benvegnu (2004) aponta o conceito de dança contemporânea atrelado à invenção como reestruturação, mudanças na configuração do tempo e do espaço, uso da tecnologia, nova estrutura de pensamento, sentimento e comportamento artístico e social. Ao se tratar de expressividade, Dantas (2005) aponta que a arte contemporânea participa de forma expressiva extra-estética, pois a expressão de valores e sentimentos torna-se diretamente provocadora e também reveladora de circunstâncias que afetam a sociedade, e não apenas de roteiros fictícios.

Ao abordar o conceito biológico, foi apontado por poucos entrevistados e também pouco encontrado nas referências, sendo mencionado por Duarte, Vasconcelos e Nascimento (2006). Segundo eles, habilidade física, compreensão e sensibilidade são as qualidades que devem ser equilibradas por um intérprete de dança contemporânea, envolvendo os aspectos fisiológicos e cinéticos. Por fim, ao tratar do conceito de técnica, o trabalho de Fortin e Long (2005) traz o conceito de forma expressa, em que a técnica de dança contemporânea pode se apoiar na singularidade do indivíduo e na experiência sensorial distintiva de cada aluno como ponto de partida para desenvolver o autoconhecimento do corpo em movimento; trazendo, então, o conceito de bailarino-intérprete.

Ainda em relação ao entendimento da dança contemporânea foi questionada a razão pela qual os entrevistados classificam o trabalho por eles desenvolvido como pertencendo a esse tipo de linguagem. As respostas apontadas pelos entrevistados variaram bastante, como por exemplo, Gabriela classifica o trabalho do grupo como dança contemporânea "pelos estudos realizados com a dança e suas linguagens, pelas desconstruções conscientes de movimentos codificados", enquanto Paulo entende que "porque ele é realizado tendo em vista o corpo como foco, com uma certa naturalidade em seus movimentos, digamos que seja uma dança saudável”.

Resultando em um processo complexo para a verificação de palavras-chave devido ao não aparecimento de semelhanças entre as respostas dos participantes. Porém, foram apontados os seguintes aspectos: estudo; consciência; emoção; desconstrução de códigos; balé clássico; liberdade; pluralismo; técnica; comunicação e transformação. Constatou-se a 
dificuldade que os coreógrafos e diretores tiveram em explicar o motivo de classificar seu trabalho como sendo dança contemporânea.

Siqueira (2006) aponta a dificuldade de explicar este conceito ao considerar a dança contemporânea como um conceito "guarda-chuva", ou seja, que abarca trabalhos coreográficos de diversos lugares e culturas. Em cada lugar existem coreógrafos e bailarinos de características distintas, senão únicas, e realizam construções coreográficas corporais conhecidas e classificadas como dança contemporânea, mas que poderiam ser classificadas com outro conceito. Portanto, uma das marcas principais é a diversidade.

A autora supracitada revela que a distinção entre os trabalhos coreográficos e as influências torna a dança contemporânea uma arte repleta de diversidade. Por este motivo cada entrevistado apresentou respostas devido ao seu desenvolvimento individual na dança, experiências únicas e influências diversas. Portanto, hodiernamente, sugere-se a nomenclatura no plural 'danças contemporâneas', devido à diversidade desta linguagem, que apesar de suas divergências, é classificada como 'dança contemporânea' no singular.

Durante a entrevista, ao explicar como se dá o processo de montagem coreográfica dos trabalhos de dança contemporânea desenvolvidos pelos coreógrafos e diretores em suas respectivas companhias ou grupos, foram de destaque e repetição as seguintes ideias: "bailarino-intérprete" e "coreografia reproduzida pelo bailarino". Conforme Tolocka e Verlengia (2006), um processo coreográfico se trata de criações sequenciais, sucessivas e com alternância de formas e movimentos, podendo esta se dar em diferentes trajetórias espaciais e temporais. É a arte de conceber os movimentos e os passos que compõe determinada dança. Nanni (2002) completa o conceito ao dizer que a criação da arte coreográfica é a expressão da dimensão humana do artista atrelada às influências do contexto sociocultural em que este está inserido

Portanto, a visão e concepção que os artistas possuem em relação a um trabalho coreográfico nunca serão iguais. Por este motivo coreografias são singulares, concebidas pela perspectiva de um coreógrafo. Este trabalho coreográfico também pode ser representado ao público de maneira distinta daquela proposta pelo criador, pois o artista que o representa nem sempre é aquele que concebe, sendo o bailarino outro artista com outras influências e características.

Ao procurar por referências, o termo 'coreografia reproduzida', citado pelos entrevistados, é encontrado apenas ao se tratar de manifestações culturais e tradições.

Sabemos que a dança é uma das artes da tradição oral. Ela é transmitida por aqueles que a praticam de forma quase automática.[...] A transmissão se dá no fazer. É assim que são passadas de geração em geração muitas de nossas tradições dançadas. É assim, igualmente, que muitas de nossas manifestações são perdidas - quando já não encontram o público/aluno para reproduzir/imitar os gestos (STRAZZACAPPA, 2001, p. 45-46).

A revisão bibliográfica revela que ao se tratar de dança contemporânea o termo 'bailarino-intérprete' citado pelos entrevistados, é o que permeia os estudos, pesquisas e trabalhos em relação ao processo coreográfico. Sendo recorrente a sigla BPI, que significa Bailarino-Pesquisador- Intérprete. Rodrigues (2003) elucida esse conceito ao dizer que o BPI é uma proposta de dança contemporânea, sendo esta uma destituição de fronteiras de técnicas corporais e de possível integração de várias linguagens artísticas, em que a criação emerge do corpo do bailarino. Nesse caso, o coreógrafo é quem dirige o processo, valorizando a singularidade e identidade do bailarino, que se torna autor da obra em conjunto com o coreógrafo.

Logo, é notável a relação que a dança contemporânea possui com este método de criação coreográfica. Os entrevistados fazem menção às palavras-chave: estudo, pluralismo e transformação e estes conceitos teóricos tem estrita ligação com o processo coreográfico que os eles mencionaram realizar, principalmente ao se tratar do bailarino-pesquisador-intérprete. 
Ao questionar quais as referências teóricas e práticas que o grupo/companhia possui para realizar trabalhos classificados como dança contemporânea, cinco dos entrevistados não possuíam referências e um entrevistado possuía como referência Martha Graham e Merce Cunningham. Por ter sido encontrada a palavra-chave 'estudos' quando questionado aos entrevistados a respeito da definição de dança contemporânea e da razão que os leva a classificar seus trabalhos como dança contemporânea, criou-se expectativa de que os mesmos fossem mencionar autores, artistas, pensadores, precursores e/ou estudiosos para embasar a construção e montagem dos seus trabalhos, tendo ocorrido, de fato, com apenas com um participante.

O entrevistado que respondeu utilizar como referência Martha Graham é o mesmo participante que apontou que o grupo estuda, participa de aulas e realiza pesquisas teóricopráticas em balé moderno, sendo Martha Graham um expoente dessa linguagem artística. Martha é reconhecida por descobrir um novo caminho para os movimentos, transformando o vocabulário e a sintaxe da dança, criando códigos diferentes dos estabelecidos pelo balé, até então vigentes e alterando o curso da história da dança no século XX (GONÇALVES, 2009).

Ao mencionar Merce Cunningham como referência, o participante também demonstra a relação de seus estudos com a dança contemporânea embasada pelo balé moderno, uma vez que Martha Graham é famosa por influenciar outros artistas da dança. Segundo Bourcier (2001), Merce Cunningham foi aluno da técnica de Graham e bailarino de sua companhia por muito tempo. Após anos de estudo e de experiência na dança seguiu seu caminho sozinho desenvolvendo uma nova técnica, uma nova linguagem e um novo modo de olhar para a dança, transformando-se, então, em um dos primeiros nomes que marcaram a dança contemporânea.

\section{Fechando as cortinas}

O conceito, assim como a ação, da linguagem denominada como dança contemporânea trará sempre mais perguntas do que respostas limitadas e conclusivas. Particularmente para os participantes deste estudo, o conceito de dança contemporânea gira em torno das palavras-chave: biológico, estudo, expressividade, pluralidade, técnica e transformação. Os critérios utilizados para a definição dos trabalhos dos grupos participantes como pertencendo à linguagem contemporânea foram: estudo; consciência; emoção; desconstrução de códigos; balé clássico; liberdade; pluralismo; técnica; comunicação e transformação. Devido à diversidade de termos, foi possível constatar a dificuldade dos diretores e coreógrafos de fornecerem respostas concisas e objetivas ao conceituarem seus trabalhos.

Em relação à identificação de referências teóricas e práticas em seus trabalhos apenas um participante indicou possuir Martha Graham e Merce Cunningham como referência, esperava que mais participantes fossem indicar referências por mencionarem a relação do estudo com o conceito de dança contemporânea. Ao constatar como se dá o processo de montagem de coreografia dos grupos participantes foram de destaque as concepções: "bailarino-intérprete" e "coreografia reproduzida pelo bailarino". A primeira faz menção ao bailarino que desenvolve - principalmente de forma prática - a ideia proposta em conjunto ao diretor e coreógrafo, e a segunda faz menção ao bailarino que executa a coreografia elaborada pelo coreógrafo/diretor.

As maiores dificuldades encontradas foram em relação às respostas fornecidas pelos participantes, em que algumas ocasiões foram subjetivas ou pouco aprofundadas. Mas, talvez, as ações tomem lugar do discurso e o 'conceito-ação' da dança contemporânea se concretize mais no palco, do que em linhas e vocábulos. 
Espera-se que este estudo sirva como embasamento e referência para a realização de pesquisas futuras, possibilitando maior entendimento e reflexão do conceito-ação da dança contemporânea a todos os envolvidos com esta linguagem artística, impulsionando demais discussões a respeito do tema.

\title{
CONCEPT-ACTION OF CONTEMPORARY DANCE
}

\begin{abstract}
The choreographic works known as contemporary dance embrace a lot of possibilities; create questions, controversies and contradictions. In this perspective, it was verified the concept of contemporary dance by the choreographic works presented by dance groups in Campo Grande (MS). This is a descriptive, qualitative research. The results show that the concept of contemporary dance that the participants have goes around the keywords: biological, studies, expressivity, plurality, technique e transformation. Confirming that the contemporary dance is a language that allows many others studies and interdisciplinarity, leaving to the involved ones the interest in unfold it.
\end{abstract}

Keywords: Dance; Concept; Concept Formation.

\section{CONCEPTO-ACCIÓN DE LA DANZA CONTEMPORÁNEA}

\section{Resumen}

Los trabajos coreográficos tenidos como danza contemporánea abarcan varias posibilidades, generan dudas, discusiones y contradicciones. En esta perspectiva, se verificó el concepto de danza contemporánea a partir de los trabajos presentados por grupos de danza en los eventos de la ciudad de Campo Grande (MS). Se trata de una investigación descriptiva, con abordaje cualitativo. Los resultados apuntan que el concepto de danza contemporánea que los participantes poseen gira entorno de las palabras clave: biológico, estudio, expresividad, pluralidad, técnica y transformación. Ratificando que la danza contemporánea es un lenguaje que posibilita diversos estudios e interdisciplinaridad, restando a los envueltos el interés en desdoblarla.

Palabras clave: Danza; Concepto; Formación de Concepto.

\section{Referências}

ANDRADE, M. M. Introdução à metodologia do trabalho científico. São Paulo: Atlas, 2005.

BOURCIER, P. História da dança no Ocidente. São Paulo: Martins Fontes, 2001.

CAMARGO, D. M. Profissional de dança: autodidata, formação artística ou formação acadêmica? 2008. 108 f. Monografia (Licenciatura em Educação Física) - Curso de Educação Física, Departamento de Educação Física, UNESP, Bauru, 2008.

CONSELHO FEDERAL DE EDUCAÇÃO FÍSICA. Resolução CONFEF no 046/2002, de 18 de fevereiro de 2002. Dispõe sobre a Intervenção do Profissional de Educação Física e respectivas competências e define os seus campos de atuação profissional. Rio de Janeiro, RJ, 
18

fev.

2002.

Disponível

em:

$<$ http://www.confef.org.br/extra/resolucoes/conteudo.asp?cd_resol=82>. Acesso em: 30 mar. 2012.

DANTAS, M. De que são feitos os dançarinos de "aquilo..." criação coreográfica e formação de intérpretes em dança contemporânea. Movimento, Porto Alegre, v. 11, n. 2, p. 31-57, maio/ago. 2005.

DUARTE, C. P.; VASCONCELOS, R.; NASCIMENTO, M. Dança em Educação Física, esporte e lazer II: dança moderna, dança contemporânea, dança jazz e sapateado. In: DACOSTA, L. (Org.). Atlas do esporte no Brasil. Rio de Janeiro: CONFEF, 2006, p. 14.31. Disponível em: < www.atlasesportebrasil.org.br/textos/262.pdf>. Acesso em: 30 mar. 2012.

FERRAZ, A. C. A arte de dançar nas aulas de Educação Física: para além de suas fronteiras em busca da construção da cidadania. 2000. 57 f. Monografia (Licenciatura em Educação Física) - Curso de Educação Física, Instituto de Biociências, UNESP, Rio Claro, 2000.

FORTIN, S.; LONG, W. Percebendo diferenças no ensino e na aprendizagem de técnicas de dança contemporânea. Movimento, Porto Alegre, v. 11 n. 2, p. 9-28, maio/ago. 2005.

FREIRE, A. V. Angel Vianna: Uma biografia da dança contemporânea. 2004. 134 f. Dissertação (Mestrado em Educação Física) - Programa de Pós-Graduação em Educação Física, UGF, Rio de Janeiro, 2004.

GARIBA, C. M. S.; FRANZONI, A. Dança escolar: uma possibilidade na Educação Física. Movimento, Porto Alegre, v. 13, n. 2, p. 155-171, maio/ago. 2007.

GIL, J. Movimento total - o corpo e a dança. São Paulo: Iluminuras, 2004.

GONÇALVES, M. G. G. Martha Graham: dança, corpo e comunicação. 2009. 144 f. Dissertação (Mestrado em Comunicação e Cultura) - Programa de Pós-Graduação em Comunicação e Cultura, UNISO, Sorocaba, 2009.

MARTINS, G. A. Manual para elaboração de monografias e dissertações. 3. ed. São Paulo: Atlas, 2002.

MINAYO, M. C. S. (Org.). Pesquisa social: teoria, método e criatividade. 25. ed. Petrópolis: Vozes, 2007.

MUNDIM, A. C. Uma possível história da dança jazz no Brasil. In: FÓRUM DE PESQUISA CIENTÍFICA EM ARTES, 3., 2005, Curitiba. Anais... Curitiba: EMBAP, 2005. v. 1, p. 96108.

NANNI, D. Dança educação: princípios, métodos e técnicas. Rio de Janeiro: Sprint, 2002.

RANGEL, N. B. C. Dança educação, educação física: proposta de ensino da dança e o universo da educação física. Jundaí: Fontoura, 2002. 
RODRIGUES, G. O método BPI (Bailarino - Pesquisador - Intérprete) e o desenvolvimento da imagem corporal: reflexões que consideram o discurso de bailarinas que vivenciaram um processo criativo baseado neste método. 2003. $172 \mathrm{f}$. Tese (Doutorado em Artes) - Instituto de Artes, UNICAMP, Campinas, 2003.

SBORQUIA, S. P.; GALLARDO, J. S. P. A dança no contexto da educação física. Ijuí: UNIJUÍ, 2006.

SIQUEIRA, D. C. Dança contemporânea: objeto de estudo da comunicação. Logos: Comunicação \& Universidade, Rio de Janeiro, ano 10, n. 18, p. 30-45, $1^{\text {o }}$ sem. 2003.

SIQUEIRA, D. C. Corpo, comunicação e cultura: a dança contemporânea em cena. Campinas: Autores Associados, 2006.

SNIZEK, A. B. A dança contemporânea na década de 1990: movimento artístico, políticas públicas e mercado. 2004. 153 f. Dissertação (Mestrado em Educação Física) - Programa de Pós-Graduação Stricto Sensu em Educação Física, UGF, Rio de Janeiro, 2004.

SOUZA, P. H. A. Dança contemporânea: percepção, contradição e aproximação. Pensar a Prática, Goiânia, v. 16, n. 4, p. 956-1270, out./dez. 2013.

STRAZZACAPPA, M. Dançando na chuva... e no chão de cimento. O ensino das artesconstruindo caminhos. Campinas: Papirus, 2001.

TOLOCKA, R.; VERLENGIA, R. Dança e diversidade humana. Campinas: Papirus, 2006.

Recebido em: 11/09/2014

Revisado em: 19/03/2015

Aprovado em: 22/09/2015

Endereço para correspondência:

fanny cacilie@ hotmail.com

Fanny Cacilie Gauna de Siqueira

Universidade Federal de Mato Grosso do Sul

Cidade Universitária, Caixa Postal 549

CEP 79070-900. Campo Grande - MS 